\title{
Hanseníase e práticas da comunicação: estudo de recepção de materiais educativos em um serviço de saúde no Rio de Janeiro*
}

Adriana Kelly Santos ${ }^{1}$

Ana Paula Goulart Ribeiro ${ }^{2}$

Simone Monteiro ${ }^{3}$

SANTOS, A.K.; RIBEIRO, A.P.G.; MONTEIRO, S. Hansen's disease and communication practices: study on the reception of educational materials at a healthcare clinic in Rio de Janeiro. Interface - Comunic., Saude, Educ., v.16, n.40, p.205-18, jan./mar. 2012.

This study analyzed the reception of educational materials among individuals with Hansen's disease who were attended within primary healthcare in the municipality of Rio de Janeiro. The aim was to identify the patients' views on the materials, and this group's meanings and representations regarding the disease. This was a qualitative study undertaken in 2008, for which the reference point was the social production of meanings. A focus group was conducted to analyze 20 materials destined for the population and for the patients. The patients discussed the neurological symptoms, the disease complications and their effects on people's lives. It was concluded that use of educational materials in group activities in healthcare clinics favors better comprehension of the clinical, psychological, social and cultural aspects of Hansen's disease and contributes towards improving the dialogue between users and the healthcare team.

Keywords: Reception. Educational and promotional materials. Communication. Leprosy.
O estudo analisa a recepção de materiais educativos por portadores de hanseníase atendidos na atenção primária de saúde no município do Rio de Janeiro. Objetivase identificar a visão dos pacientes sobre os materiais, os significados e as representações deste grupo sobre a doença. Trata-se de uma pesquisa qualitativa, realizada em 2008, a qual adotou o referencial da produção social dos sentidos. Foi realizado um grupo focal para análise de vinte materiais destinados à população e aos pacientes. Os pacientes discutiram sobre os sintomas neurológicos, as complicações da doença e seus efeitos na vida das pessoas. Conclui-se que o uso dos materiais educativos nas atividades de grupo no serviço de saúde favorece a melhor compreensão de aspectos clínicos, psicológicos e socioculturais sobre a hanseníase, e contribui para potencializar o diálogo entre usuários e a equipe de saúde.

Palavras-chave: Estudo de recepção. Materiais educativos e de divulgação. Comunicação. Hanseníase.

\footnotetext{
Elaborado com base em Kelly-Santos (2009). A pesquisa foi realizada com o apoio do CNPq, por meio de bolsa de apoio à formação de doutores.

${ }^{1}$ Departamento de Medicina e Enfermagem, Universidade Federal de Viçosa. Av. PH Rolfs, s/n, campus universitário. Viçosa, MG, Brasil. 36.570-000. adrianakellyminas@ hotmail.com

2 Escola de Comunicação, Universidade Federal do Rio de Janeiro, RJ. ${ }^{3}$ Laboratório de Educação e Ambiente em Saúde, Instituto Oswaldo Cruz, Fundação Oswaldo Cruz.
} 


\section{Introdução}

A hanseníase representa um grave problema de saúde pública no Brasil, por ser endêmica em diversas regiões do país e por provocar graves danos físicos e sociais às pessoas acometidas por essa enfermidade. Além disso, historicamente, este agravo se associa às diversas formas de segregação social. Desde 1976, o Ministério da Saúde substituiu o termo lepra por hanseníase nos atendimentos de serviços de saúde e nas campanhas de divulgação sobre a doença (televisão, rádio e distribuição de materiais educativos), visando minimizar o preconceito e as atitudes de discriminação. As campanhas têm sido umas das principais ações para ampliar o conhecimento da nova denominação e aumentar a detecção de novos casos. Neste estudo, investigamos os processos comunicativos implementados nos programas de controle do governo, com base na análise da recepção de materiais educativos feita pelos portadores de hanseníase.

Partimos da premissa de que os materiais educativos atuam como mediadores na produção de sentidos em torno dos discursos sanitários, na medida em que são dispositivos pelos quais determinados valores, conceitos e políticas ganham status de verdade e delineiam práticas sociais específicas. Nesse processo, a recepção é compreendida como uma dimensão ativa, um lugar de reconhecimento construído na situação de interlocução (Leal, 1995). Emissor e receptor, denominados interlocutores, interagem como sujeitos que ressignificam suas histórias e seus saberes. As condições de produção e recepção são, portanto, indissociáveis e construídas histórica, política e culturalmente em cada contexto social (Martin-Barbero, 2003).

No campo da comunicação e saúde, as pesquisas de recepção ainda são escassas, embora sejam estratégicas para problematizar como se dá a interação entre produtores ou consumidores de discursos, e como, nessa relação, acontece a produção de sentidos sobre as doenças e as práticas preventivas e promotoras de saúde. Com a intenção de contribuir nessas questões, este artigo objetiva refletir sobre a visão dos pacientes de hanseníase e os materiais educativos no contexto de um serviço de saúde, e identificar os significados e as representações deste grupo sobre a doença.

\section{Estratégias metodológicas}

Trata-se de uma pesquisa qualitativa, realizada em 2008, na Atenção Primária do município do Rio de Janeiro. O serviço foi escolhido por se situar em área endêmica, possuir um programa de controle que oferece diagnóstico, tratamento, grupos de ajuda mútua e uma equipe multidisciplinar. Os pacientes foram selecionados por estarem em tratamento com a poliquimioterapia (PQT) ou em acompanhamento das reações imunológicas. Na escolha dos vinte impressos analisados, que integram o acervo de 276 materiais educativos desta pesquisa (Kelly-Santos et al., 2009), levaram-se em conta: o formato, o público, os temas, as entidades produtoras e seu uso no serviço investigado.

Para análise destes materiais, foi realizado um grupo focal com oito pacientes. Aconteceram dois encontros no posto de saúde, com duas horas de duração, sob coordenação da pesquisadora Eliana Vargas do Laboratório de Educação em Saúde e Ambiente, do Instituto Oswaldo Cruz, Fiocruz. A primeira autora observou e registrou os encontros, que foram gravados e transcritos.

A técnica de grupo focal (Minayo, 2000) favoreceu a compreensão das experiências dos sujeitos acerca da doença e a negociação dos sentidos no contexto da recepção. A dinâmica constituiu na leitura de três conjuntos de materiais, buscando observar as mediações intrínsecas ao processo de recepção. Para tal, foi mapeado o modo como os pacientes hierarquizam os temas e a relação estabelecida com suas experiências. Na qualificação destes elementos foram analisados os aspectos relativos ao produto (formato, diagramação, objetivos, público), ao contexto de circulação (acesso ao material, formas de distribuição e de uso) e à apropriação das mensagens (conteúdos, forma, credibilidade).

As informações coletadas foram analisadas e categorizadas em unidades temáticas, posteriormente sistematizadas em núcleos semânticos (Minayo, 2000). Ao conjunto de impressos foi aplicada a análise dos dispositivos de enunciação (Verón, 2004; Pinto, 1999), que possibilitou descrever como as entidades discursivas do enunciador (sujeito da enunciação), do destinatário (sujeito falado) e do referente 
(sujeitos do enunciado) foram representadas nos materiais, além das operações de linguagem que demarcam as posições de saber e poder nos discursos. Os relatos dos entrevistados foram indicados pelas variáveis sexo e idade. Os atendimentos e os grupos de ajuda mútua realizados no programa de controle investigado foram observados como parte da recepção de materiais. Este estudo foi aprovado pelo Comitê de Ética em Pesquisa da Ensp/Fiocruz.

\section{Resultados}

\section{O posto de saúde, o programa e os participantes}

A pesquisa aconteceu em um Posto de Saúde da Zona Oeste do município do Rio de Janeiro, cujo programa de hanseníase é um dos Polos de Prevenção de Incapacidades da região, oferecendo diagnóstico, tratamento (poliquimioterapia - PQT, prevenção de incapacidades, reabilitação) e grupos de ajuda mútua. A equipe responsável pelos atendimentos era composta por: duas enfermeiras, duas auxiliares de enfermagem, uma médica, uma terapeuta ocupacional e uma psicóloga.

Na época do estudo, havia 39 pacientes registrados no programa. Desse total, 13 participaram da pesquisa. Destes, oito compareceram ao grupo focal para a análise dos materiais educativos, sendo quatro homens e quatro mulheres, entre 26 e 63 anos. O estado civil variava entre casados (6/8), viúva (1/8) e solteira (1/8). A escolaridade predominante era o Ensino Fundamental incompleto (6/8), havendo uma pessoa com Ensino Médio completo e outra sem alfabetização formal. Dos participantes, quatro estavam inseridos no mercado formal (ajudante de cozinha, agente comunitária de saúde, cozinheiro e vigia), dois estavam desempregados, um estava aposentado e outra era dona de casa. Todos os integrantes do grupo apresentavam as formas multibacilares da hanseníase, estavam em acompanhamento de reações imunológicas, e manifestavam algum grau de incapacidade física (redução da força muscular nos braços e nas pernas, alteração da sensibilidade, perda da acuidade visual, atrofias severas de pés e mãos); apenas um tratava-se simultaneamente com a PQT. Em virtude das incapacidades físicas, dois pacientes estavam afastados do trabalho pela previdência social e quatro aguardavam o benefício auxílio-doença.

\section{Descrição dos materiais educativos}

Os vinte impressos analisados foram produzidos por instituições do governo, organizações não governamentais (ONG), empresas privadas, grande parte delas em parceria interinstitucional. Deste total, 17 são destinados ao público em geral e três aos portadores de hanseníase. Os formatos são variados: cinco

${ }^{4}$ Agradecimentos a Gilson Machado, da VideoSaúde Distribuidora da Fiocruz/ICICT, que fotografou e digitalizou os cartazes que integram o Acervo Eletrônico de Materiais Educativos sobre Hanseníase. cartazes ${ }^{4}$, cinco panfletos, três folhetos, três cartilhas, dois cartões telefônicos, um cartão postal (Quadro 1). A diagramação é diversificada, tanto no uso de desenhos, fotografias e tipos de letras, como nos gêneros e nas mediações existentes, incluindo: a "fotonovela", "lógica testemunhal", "cotidianidade", "familiaridade" e "cultura" (Verón, 2004; Martin-Barbero, 2003).

As mensagens abordam os sinais e sintomas por meio de textos explicativos, fotografias de lesões em partes do corpo humano, desenho da mulher se queimando no fogão e de pessoas fazendo o autoexame. As informações sobre tratamento e cura são apresentadas recorrentemente pela fotografia de medicamentos e desenho de um paciente atravessando a faixa de chegada com 
a palavra "cura". As dimensões socioculturais (integração social, preconceito e direitos) são indicadas pelo uso de fotografias de ex-pacientes, artistas e pessoas sem deformidades físicas de diferentes sexo/ gênero, cor/raça e idade. Também são construídas pela associação dos termos lepra e hanseníase, e pelo emprego de desenhos e frases que representam pessoas com uma "vida normal". A prevenção de incapacidades é abordada, frequentemente, por desenhos que orientam para o autocuidado. $\mathrm{Na}$ explicação destes conteúdos, predomina: o saber biomédico, a linguagem técnica e prescritiva, o uso de perguntas e respostas, frases afirmativas e imperativas.

Quadro 1. Materiais educativos sobre hanseníase

\begin{tabular}{|c|c|c|c|c|}
\hline & Público & Formato & Título & Produtor \\
\hline 1 & Portadores de hanseníase & Cartilha 02 & $\begin{array}{l}\text { "Hanseníase. Cuidados para evitar } \\
\text { complicações" }\end{array}$ & (NUTES/UFRJ) \\
\hline 2 & Portadores de hanseníase & Cartilha 30 & $\begin{array}{l}\text { "Orientações sobre hanseníase. Você diria que } \\
\text { já tive hanseníase?" }\end{array}$ & (GT/CONASEMS/HANSEN); \\
\hline 3 & Portadores de hanseníase & Cartilha 36 & "Hanseníase e Direitos Humanos" & (Ministério da Saúde) \\
\hline 4 & Público em geral & Cartilha 05 & $\begin{array}{l}\text { "Caretas. Cyinthia Patrícia vence a } \\
\text { hanseníase" }\end{array}$ & (IBISS/Reprhan) \\
\hline 5 & Público em geral & Folheto 18 & "O que é hanseníase?" & $(S M S / R J)$ \\
\hline 6 & Público em geral & Folheto 22 & "Um toque de saúde: hanseníase tem cura" & (Ministério da Saúde) \\
\hline 7 & Público em geral & Folheto 61 & "Hanseníase" & (Ministério da Saúde) \\
\hline 8 & Público em geral & Panfleto 04 & $\begin{array}{l}\text { "Ministério da Saúde. Mancha na pele pode } \\
\text { ser hanseníase. Procure um posto de saúde" }\end{array}$ & (Ministério da Saúde) \\
\hline 9 & Público em geral & Panfleto 36 & $\begin{array}{l}\text { "Hanseníase. Você pega, a gente trata, você } \\
\text { se cura" }\end{array}$ & (Ministério da Saúde) \\
\hline 10 & Público em geral & Panfleto 46 & "Você tem manchas dormentes no corpo?" & (SMS-RJ/Fiocruz) \\
\hline 11 & Público em geral & Panfleto 58 & $\begin{array}{l}\text { "Em caso de suspeita de hanseníase procure o } \\
\text { posto de saúde" }\end{array}$ & (SMS/Vale Sul). \\
\hline 12 & Público em geral & Panfleto 64 & $\begin{array}{l}\text { "Manchas na pele, que não doem nem } \\
\text { coçam. Isso pode ser hanseníase" }\end{array}$ & (Unimed/Morhan); \\
\hline 13 & Público em geral & Cartaz 5 & $\begin{array}{l}\text { "Hanseníase. Diagnóstico precoce sem deixar } \\
\text { marcas" }\end{array}$ & (SBD/NLR-Brasil); \\
\hline 14 & Público em geral & Cartaz 12 & "Você diria que já tive hanseníase?" & (GT/CONASEMS/HANSEN); \\
\hline 15 & Público em geral & Cartaz 16 & $\begin{array}{l}\text { "Hanseníase. Quem não tem pode combater. } \\
\text { Quem tem pode curar" }\end{array}$ & $(F U A M)$ \\
\hline 16 & Público em geral & Cartaz 30 & "Hanseníase tem cura" & (MS) \\
\hline 17 & Público em geral & Cartaz 33 & "Hanseníase" & (SES/AL). \\
\hline 18 & Público em geral & $\begin{array}{l}\text { Cartão } \\
\text { Telefônico } 01\end{array}$ & "Hanseníase temos que saber reconhecer" & (MS e Brasil Telecom). \\
\hline 19 & Público em geral & $\begin{array}{l}\text { Cartão } \\
\text { Telefônico } 02\end{array}$ & "Hanseníase temos que saber reconhecer" & (MS e Brasil Telecom). \\
\hline 20 & Público em geral & $\begin{array}{l}\text { Cartão-postal } \\
01\end{array}$ & $\begin{array}{l}\text { "Me curei da Hanseníase e hoje me sinto até } \\
\text { mais bonita" }\end{array}$ & (IBISS/Reprhan) \\
\hline
\end{tabular}

\section{O olhar dos pacientes: metáfora da "fogueira"}

Ao iniciar a avaliação dos materiais, uma participante relatou que viu um cartaz, em uma das unidades de referência em hanseníase, que mostrava algumas lesões com os dizeres "Hanseníase tem cura". Ao ler este enunciado, comentou com a profissional que a atendia: "esse cartaz está mentindo, essa doença não tem cura nada". A partir dessa lembrança, ela sinalizou que participaria do grupo focal para "jogar esses materiais na fogueira", porque "eles não falam a verdade sobre a doença" (Mulher, 44 anos). 
A metáfora da "fogueira" fomentou o diálogo sobre as experiências dos participantes em relação às mensagens veiculadas. A questão "Para que servem esses materiais?" orientou as discussões quanto aos elementos comunicacionais, às informações necessárias para o esclarecimento da doença e à preferência pelos materiais.

O cartão-postal 1, o panfleto 64, o cartaz 33 e as cartilhas 2 e 5 foram eleitos os mais adequados em virtude dos temas e do modo como se constrói a comunicação com o leitor. Os panfletos e folhetos mais simples, sem muitas dobras, com frases curtas, diretas e letras grandes, despertaram a atenção das pessoas. Verificou-se que estes elementos contribuíram para facilitar a compreensão dos textos e a interação com o material. Os participantes consideraram estes formatos adequados tanto para a população como para os pacientes.

Em relação à dobra do panfleto 46 , os pacientes relataram que este recurso não serviu para despertar a curiosidade, tal como idealizado pelo produtor - "Nós que estamos aqui lendo os materiais não tivemos essa sensibilidade de perceber que as fotos estavam debaixo da dobra. Imagina quem não tem nada a ver com esse assunto" (Mulher, 44 anos). Os cartazes foram considerados como parte da cultura dos serviços de saúde eficientes, de certa forma, na mobilização da atenção do público, embora os integrantes deste estudo reconheçam que nem sempre este tipo de material é lido.

Os membros do grupo consideraram o formato de cartilha o mais apropriado para os pacientes por possibilitar o melhor entendimento sobre os sintomas neurológicos e sobre a prevenção de incapacidades, entre outros assuntos. Segundo eles, esses conteúdos favorecem a compreensão de determinados aspectos da doença e a adesão ao tratamento. Notou-se que alguns temas relevantes para os pacientes (como sexualidade, efeitos dos medicamentos e reações imunológicas) são poucos explorados nos materiais.

O formato cartilha, associado ao gênero fotonovela, foi bem aceito e mediou o debate sobre os sintomas neurológicos, a relação entre a doença e as condições sociais, o uso do termo lepra e da imagem de artistas. Uma participante, ao ver a fotografia do cantor Ney Matogrosso no panfleto 22 , relatou que a imagem de artistas não dá credibilidade à informação e "as pessoas podem pensar que eles estão ali pelo cachê". Essa opinião contrasta com as observações de campo, pois várias pessoas, ao verem a foto do cantor no material, perguntavam sobre a doença e se ele teve hanseníase. Esclarecia-se, então, que o artista não teve doença, mas que é voluntário do Movimento de Reabilitação das Pessoas Atingidas pela Hanseníase - Morhan. Neste caso, o artista parece ter conferido credibilidade ao material.

Em relação aos cartões telefônicos, o grupo valorizou as fotografias de ex-pacientes e foi enfático ao responder que este veículo não chama atenção das pessoas: "ninguém lê o que está escrito", "as letras são muito pequenas".

Figura 1. "Hanseníase - temos que saber reconhecer"

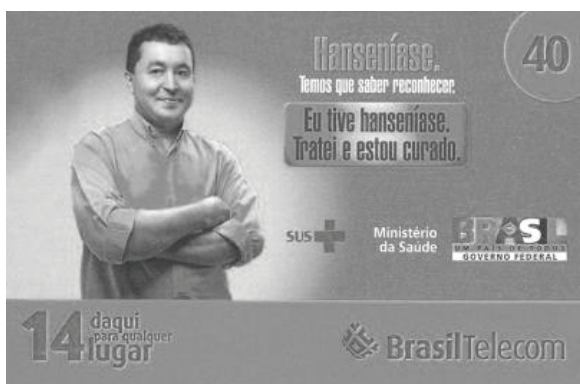


Já o cartão-postal 1 despertou o interesse das mulheres mais pela fotografia de uma ex-paciente e pela relação simétrica entre enunciador-destinatário do que pelo seu formato.

Figura 2. "Me curei da hanseníase e hoje me sinto até mais bonita"

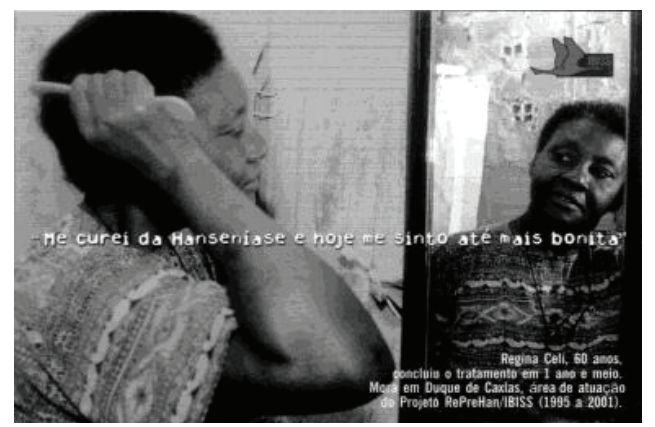

O enunciado "Me curei da Hanseníase e hoje me sinto até mais bonita" desse material remeteu ao debate sobre os sentimentos vividos frente ao diagnóstico e sobre o cuidado de si.

"Quando descobri que eu estava com hanseníase há um ano, eu me sentia muito deprimida, principalmente porque eu engordei quase trinta quilos. Hoje, eu não estou curada da hanse não, mas eu estou me sentindo melhor. Estou com gosto de pintar o meu cabelo, de fazer as minhas sobrancelhas, sair de casa." (Mulher, 44 anos)

Este depoimento estimulou a discussão sobre a necessidade de os pacientes aprenderem a conviver com as mudanças em seu corpo e em sua vida, isto é, de enfrentarem as situações limitantes, e as perdas irreparáveis, como, por exemplo: redução da força física, mudança na imagem corporal, seja pelo ganho excessivo de peso em decorrência do uso da predinizona ou pelas deformidades. Contudo, nas observações dos atendimentos, foi identificado o predomínio de uma abordagem orientada para o diagnóstico da doença e a cura medicamentosa, em detrimento da atenção integral e do cuidado humanizado à saúde. Tal lacuna indica a necessidade de as equipes de saúde incluírem, em suas práticas, a dimensão do cuidado de si (Foucault, 2006). Na medida em que o cuidado de si se coloca como uma possibilidade de o sujeito (profissional ou paciente) buscar, no conhecimento de seus afetos, experiências e, na relação com outro, novas formas para lidar com as adversidades e os riscos inerentes à vida (Canguilhem, 2005).

\section{Dispositivo de enunciação e o vínculo com o receptor: modos de mostrar e viver}

\section{Sinais e sintomas}

A análise do panfleto 64, cartaz 33 e das cartilhas 2 e 5 mobilizou a percepção dos sinais e sintomas e dos efeitos da doença na vida das pessoas. Os pacientes elogiaram o panfleto 64, que apresenta uma pessoa segurando uma pasta, seguida da frase "segure objetos de peso médio para checar se tem força nas mãos", e de uma pessoa subindo um degrau com a frase "teste a força dos pés, subindo degraus". Para eles, estes enunciados expõem claramente o que acontece no cotidiano e podem auxiliar no reconhecimento dos sintomas neurológicos.

A partir desse material, o grupo discutiu o sintoma neurológico referente à redução da força muscular, uma realidade vivida pelos participantes que provoca limitações nas atividades diárias. Já a alteração da sensibilidade térmica e tátil, referida como "perda de sensibilidade", foi discutida pela leitura do cartaz 33. 
Figura 3. "Hanseníase uma questão de sensibilidade"

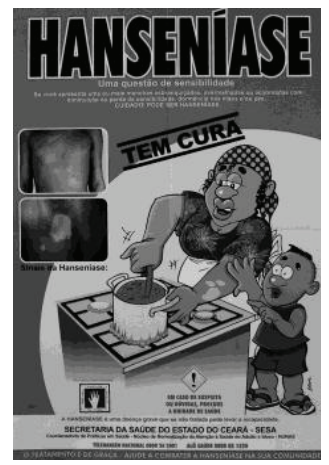

Segundo os pacientes, este cartaz pode auxiliar no reconhecimento deste sintoma, uma vez que mostra o que acontece na realidade: "a pessoa se queima e não sente dor".

“[a imagem] Não é tão agressiva. É uma realidade que as pessoas possam vir até prestar mais atenção. Também mostra o risco que a pessoa corre". (Mulher, 44 anos)

"É importante porque a pessoa está se queimando e acha que é por acaso, mas não é não! Eu cheguei todo queimado aqui". (Homem, 56 anos)

Para os pacientes, os sintomas neurológicos, expressos nos materiais e denominados como "dor, cansaço, câimbras, fraqueza, perda de força, perda de sensibilidade", precisam ser mais trabalhados na comunicação sobre a hanseníase, pois estas manifestações, na maioria das vezes, são confundidas com outras enfermidades, como reumatismo, osteoporose e problema de coluna. O debate sobre esses sintomas suscitou o diálogo sobre as diferenças de gênero nas experiências com o agravo, expresso na indagação "Quem sente mais dor: o homem ou a mulher?", e na fala:

"Mas eu estou falando na questão do homem. A mulher está em casa, doméstica. Que nem essa senhora aí do fogão. O homem tem que sair para trabalhar [se fica doente] tem que parar de trabalhar". (Homem, 56 anos)

Embora os participantes afirmem que a hanseníase se manifesta de forma igual entre homens e mulheres, acreditam que o modo como cada um vive é diferente. Por exemplo, a leitura da frase "Me curei da hanseníase e hoje me sinto até mais bonita" suscitou relatos sobre as diferenças no modo como os homens e as mulheres vivenciam os efeitos das reações imunológicas, dos medicamentos e das lesões no corpo. Para as mulheres, as mudanças na estética, concernentes à alteração na imagem corporal, interferem na autoestima, no estado emocional, na sexualidade e na interação social. Já os homens consideraram que a impossibilidade ou a redução da força física altera o seu desempenho tanto no trabalho como no papel de provedor da família, influenciando na sexualidade e nas relações familiares e sociais.

Estas constatações também foram observadas nos grupos de ajuda mútua realizados no serviço investigado. O tema da sexualidade foi relacionado aos efeitos de medicamentos e/ou alterações no estado emocional: "baixa auto-estima, depressão, irritação, medo de rejeição, revolta". Uma participante deste grupo associou a diminuição do desejo sexual ao uso dos medicamentos. Outra integrante contou que seu marido ficou muito "revoltado" ao descobrir que estava com hanseníase e que "abandonou o tratamento por associá-lo a falta de ereção".

Os participantes supõem que há mais homens do que mulheres com a doença, em função de suas observações durante as idas nos serviços de saúde. Isso é confirmado pelos dados do Ministério 
da Saúde. Dos 31.328 casos novos registrados em julho de 2009, 49\% eram de homens, e 38\%, de mulheres adultas (Brasil, 2009). Apesar destes dados, verificamos que a comunicação para esse público ainda é escassa. A análise dos 276 materiais do Banco referido comprova a reduzida veiculação tanto da imagem de homens como de temas de interesse desse segmento. Tal constatação foi endossada por um dos homens participantes deste estudo, que explicitou sobre a falta de materiais para o público masculino.
"Além das manchas seria bom se mostrasse o enfraquecimento, como se a pessoa estivesse trabalhando e sentisse dor, fraqueza. Por exemplo, nós ficamos sem sensibilidade nos dedos. Então o desenho vai mostrar a pessoa pegando o objeto, segurando uma enxada e ela vai cair. Porque o homem demora um tempo para perceber. Ele vai ver que está fraco. Mostrar a atividade corporal do homem trabalhando". (Homem, 56 anos)

As questões ligadas à sexualidade, ao cuidado pessoal, ao lazer e ao trabalho provocam sentimentos de "impotência" e "inutilidade" em pacientes de ambos os sexos, alterando o estado emocional e as relações sociais. Mas a hanseníase afeta de forma diferente a vida de homens e mulheres. O modo como cada um vai significar e vivenciar os efeitos da doença, de suas sequelas e dos medicamentos é distinto em função das relações de gênero e das representações socioculturais dessa enfermidade, construídas historicamente.

Nesse sentido, na formulação de práticas comunicativas mais contextualizadas, considera-se relevante a correlação entre os sintomas e efeitos da hanseníase, como, por exemplo: dor, diminuição da força física, sequelas e o afastamento do trabalho; a sexualidade; as relações de gênero; além de mostrar a realidade de modo mais concreto. Para tal, a situação epidemiológica do agravo e as condições sociais, culturais e subjetivas dos destinatários precisam ser mapeadas e incluídas como elementos do planejamento comunicacional.

Outro aspecto debatido refere-se ao uso de fotografias de lesões em partes do corpo humano. Uma entrevistada descobriu que estava com hanseníase quando viu um cartaz com uma mancha esbranquiçada semelhante às manchas do seu corpo. No entanto, para alguns participantes, essas imagens podem provocar "medo", "horror" e "desinformação".

\footnotetext{
"Engraçado, essa reação aqui [aponta para o corpo] não é igual a nenhuma reação dessas manchas do cartaz". (Mulher, 42 anos)

\begin{abstract}
“Isso aí já é um outro estágio da doença. Vamos dizer da década lá de trás. [...] Eu acho que deve mostrar as manchas, mas no início da doença e não uma coisa assim igual do cartaz. Porque, mesmo a pessoa tendo uma manchinha, ela nunca vai saber que é a hanseníase, porque não está daquele jeito exagerado". (Mulher, 44 anos)
\end{abstract}

Essa interpretação também foi encontrada nos estudos de Claro (1995) sobre representações sociais da hanseníase. Em nossa pesquisa, pondera-se que o predomínio do discurso biomédico, que focaliza a lesão e a fragmentação do corpo, na comunicação sobre a doença, pode minimizar a compreensão de outros fatores intrínsecos a este agravo, além de desconsiderar a abordagem integral da pessoa (KellySantos et al., 2009b).

Embora os produtores privilegiem esse saber, a leitura coletiva dos materiais favoreceu o maior conhecimento dos pacientes acerca: dos sinais, sintomas e sua correlação com as formas clínicas da doença; a percepção dessas manifestações em seu corpo; os efeitos das sequelas e dos medicamentos, além dos cuidados necessários no tratamento. A interação dos participantes com o material permitiu a emergência de diferentes representações e experiências, mas, sobretudo, ampliou o diálogo entre a equipe de saúde e os pacientes. Este enfoque, quando aplicado a outras atividades de prevenção e promoção, pode construir práticas de saúde mais horizontais e participativas. 


\section{Tratamento e cura}

A partir do panfleto 46 , que apresenta uma foto da cartela de medicamentos em reforço à ideia de cura, o binômio tratamento-cura foi amplamente discutido pelo grupo. Segundo uma participante, o "comprimido branquinho", a dapsona, provoca muitas reações. Em sua opinião, "deveria ser usado outro medicamento mais eficaz, pois esse remédio pode até resolver o problema da hanseníase, mas causa outras, como infecção urinária e febre" (Mulher, 42 anos). Para os membros do grupo é fundamental que os materiais destinados aos pacientes expliquem as reações de forma clara e detalhada, com vistas a ajudá-los a lidar melhor com essa situação. No entanto, ponderam que a veiculação deste conteúdo, nos cartazes para a população, pode assustar e dar medo.

$\mathrm{Na}$ visão do grupo, é necessário esclarecer, já no começo do tratamento, os efeitos dos medicamentos e as complicações da doença (neurites, incapacidades físicas etc.), afinal eles têm "o direito de saber o que pode acontecer com eles". Esta medida ajudaria na melhor compreensão da doença e dos cuidados necessários, visando à participação ativa do paciente no tratamento. Eles argumentaram que os profissionais de saúde falam muito pouco sobre esses aspectos.

"O médico tem medo de falar a verdade sobre a reação do remédio e a pessoa não voltar mais ao tratamento". (Mulher, 42 anos)

"Eu acho assim: os médicos, o pessoal da área de saúde, têm que aprender [...] a falar com o paciente de uma forma mais clara, não escondendo algumas coisas. Eu acho que o paciente se sente melhor em saber como é que ele vai passar aquele tempo todo [tratamento]". (Mulher de 44 anos)

Para os participantes é preciso falar abertamente sobre a gravidade da doença. Esta opinião foi endossada pela leitura da frase "você pode levar uma vida normal" (cartilha 2). As diferenças entre o enunciado e as experiências pessoais se evidenciaram neste ponto. As mudanças físicas, psicológicas e sociais decorrentes da hanseníase impedem justamente uma "vida normal": "Eu trabalhava na cozinha, antes eu servia a rampa. Hoje eu não agüento mais aquele prato na mão" (Mulher, 58 anos).

A discussão sobre tratamento-cura foi ampliada após a leitura da frase "quantas amigas minhas ainda ignoram que hanseníase tem cura e que o tratamento é gratuito?" (cartilha 5). Um dos participantes comentou: "a frase está certa ao explicitar que o tratamento é gratuito, mas está errada, está mentindo, ao dizer que a doença tem cura. Se uma pessoa pega a hanseníase, ela vai achar que é verdade e, quando a doença for evoluindo, vai ver que é mentira" (Homem, 42 anos). Outros concordaram com esse ponto de vista, alegando que essa informação é uma "propaganda enganosa".

“Medicamento. Ótimo! Não estou contagiando ninguém. É bom! Mas acontece o seguinte: e a sequela? Você acha que está 100\% bom para trabalhar e vê que não está". (Homem, 56 anos)

Esse debate é reforçado pela pergunta sobre o significado da imagem "cura-vencedor" da cartilha 2.

Figura 4. "Cura"

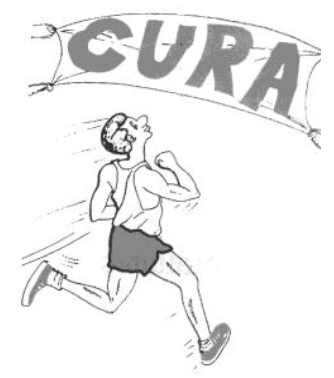


Inicialmente, esta ideia foi considerada verdadeira no sentido de as pessoas retratarem a cura como "algo desejado", "algo a se conseguir", "uma vitória". Todavia, após a leitura da frase "quanto mais regular o tratamento, mais rápida será a cura", a noção de cura foi questionada. A diferença entre o desejado e a realidade vivida pelos pacientes levou os participantes a considerarem que essa imagem não os representa. Quer dizer, eles não se reconhecem como vencedores, porque não se sentem curados de fato, pois, a cada dia, aparece uma "coisa nova", prolongando o tempo de tratamento e o sofrimento relacionado aos efeitos da doença.

\begin{abstract}
"Quando terminei de tomar o remédio e comecei a sentir as dores e desacreditei na cura. Você toma o remédio para ficar boa. Assim a gente acha. Igual a tuberculose. Mas a hanseníase não é assim. Só que a vida continua, se olhar para trás tem muita gente pior, com estágio avançado da doença, com seqüelas". (Mulher, 58 anos)
\end{abstract}

Nos depoimentos e nos materiais educativos, fica evidente a premissa da saúde como ausência de doença e a da cura medicamentosa, isto é, a ideia de que a vida dos órgãos retornaria ao estado anterior ao adoecimento, ao normal (Canguilhem, 2005). Esse ideal de cura precisa ser relativizado, dado que, em muitos casos, a reabilitação da parte do corpo afetada pelo bacilo ou pelos efeitos das reações imunológicas pode não voltar a funcionar como antes. Essa evidência remete à necessidade de se rever a atenção aos portadores de hanseníase vigente nos serviços de saúde. Isso implicaria promover uma prática de cuidado que trate a pessoa, sem transformá-la em objeto do saber biomédico. Esse tipo de abordagem requer, dos sujeitos, profissionais de saúde e pacientes, a participação ativa no processo de cuidado, esta compreendida como o exercício constante do diálogo e da escuta (Bakhtin, 2006).

As representações socioculturais relativas ao tratamento-complicações-cura configuram um mosaico na dinâmica dessa doença sistêmica e com alto poder incapacitante (Claro, 1995). Sublinhase que vários participantes deste estudo apresentavam alguma incapacidade física. Certamente esse aspecto determinou a emergência de temas considerados "verdadeiros" em relação a outros. Nesse processo de produção e negociação de saberes, a correlação entre as complicações da doença (reações, efeitos de medicamentos, incapacidades físicas etc.) e o trabalho foi um dos assuntos centrais na análise dos materiais.

Para homens e mulheres entrevistados, o trabalho é um marcador social relevante nas trocas simbólicas. A inserção no mercado profissional possibilita a sobrevivência dessas pessoas, mas, sobretudo, é um elemento de pertencimento ao grupo social, que permite estabelecer laços sociais, trocar conhecimentos e criar identidades culturais, seja por meio de categorias profissionais ("vigia", "cozinheiro(a)", "dona de casa", "agente de saúde"), seja pela situação de trabalho ("trabalhador", "autônomo", "desempregado", "aposentado", "encostado").

O fato de eles estarem afastados do trabalho, recebendo o benefício social, ou não estarem inseridos no mercado (formal e informal), foi percebido como um motivo de grande "preocupação", "tristeza", "depressão", "sentimento de inutilidade", "impotência" e de cerceamento dos direitos sociais. Em certa medida, as complicações da doença - "perda de força e de sensibilidade", "dor intensa" - foram relacionadas com a impossibilidade de se manter no trabalho ou de conseguir uma nova inserção. Embora nesta pesquisa tenham sido identificadas várias implicações dos efeitos da hanseníase na história de trabalho do paciente, esse aspecto é pouco considerado nos atendimentos dos programas e nos próprios materiais educativos.

\title{
Os sentidos da lepra e hanseníase
}

A palavra hanseníase foi cunhada pelo saber médico-sanitário sob o argumento de que um novo nome criaria uma nova representação para a doença. $O$ uso do radical estrangeiro hansen, uma homenagem ao descobridor do bacilo, Gerhard H.A. Hansen, tem a intenção de conferir uma conotação "científica" à doença. Compreende-se que a incorporação de uma palavra externa às 
referências culturais da maioria da população brasileira traz consigo toda a força e poder da cultura que representa, sendo adotada para legitimar determinados saberes (Bakhtin, 2006).

Como afirma Sontag (1984, p.100), "o conceito de doença nunca é inocente". No caso da lepra, historicamente, o nome da doença, no seu sentido religioso e mítico, representava a síntese do mal, e as pessoas que padeciam desta enfermidade eram fortemente estigmatizadas. É compreensível, portanto, que os pacientes prefiram o uso do termo hanseníase como atenuante das marcas socioculturais da doença.

Em termos da comunicação sobre a mudança terminológica, assinala-se que a primeira campanha de divulgação de massa com o nome hanseníase ocorreu em 1988, 12 anos após sua adoção pelo Ministério da Saúde, sem, contudo, associá-lo ao termo lepra. Em entrevista dada à pesquisa de Moreira (2005), Abraão Rotberg, o médico que propôs a mudança terminológica, afirma que seria muito importante que as autoridades sanitárias, no decorrer das campanhas, associassem os dois termos, ressaltando que a doença tem tratamento e cura sem necessidade de internação.

A leitura da "fotonovela", escolhida para análise por ser um dos materiais que menciona a palavra lepra, gerou diferentes opiniões sobre esse assunto.

"Eu acho que só chamar de lepra é uma coisa muito agressiva. Agora se você associar a lepra à hanseníase, contando um pouco da história, aí a coisa muda de figura". (Mulher, 44 anos)

"Eu também acho. Só que agora foi o que eu falei, ficou mais bonito (refere à hanseníase)". (Mulher, 58 anos)

"É um feio arrumadinho. Porque o nome lepra é um nome feio gente! É horroroso!". (Mulher, 44 anos)

Essas falas explicitam que o sentido da palavra é dado em seu contexto e "há tantas significações possíveis quanto contextos possíveis" (Bakhtin, 2006, p.109). Igualmente, traduzem que o discurso da hanseníase, em alguns casos, possibilita ocultar os significados e representações negativas atribuídas à lepra, além de operar como uma metáfora na construção de novas imagens, palavras e formas de endereçamento ao outro. Ratifica essa premissa o fato de os participantes considerarem positivo as pessoas desconhecerem que a hanseníase é a lepra. Por outro lado, eles demonstraram certa dificuldade em lidar com a questão da nomeação da doença. Alguns participantes afirmaram que se sentem discriminados quando outras pessoas "descobrem" que o que eles têm, na realidade, é lepra.

"[hanseníase] É um nome novo que ninguém tem o entendimento. Quem sabe mais são as pessoas que fazem o tratamento. Quem faz o tratamento tem certeza que a hanseníase é lepra e procura acreditar na hanseníase e deixar a lepra de lado para não ficar triste". (Homem, 58 anos)

"Quando você fala o nome lepra, eles ficam retraídos. Uma vez eu conversava com uma amiga no ônibus dizendo que estava tratando de hanseníase. Expliquei que antigamente chamava lepra e que agora ficou mais bonitinho. A moça que estava sentada perto da gente saiu e foi sentar em outro lugar [...] Você pode trabalhar, mas não pode falar que tem a doença, porque as pessoas têm preconceito". (Mulher, 58 anos)

Estes depoimentos revelam o dilema subjetivo que o paciente enfrenta. É como se tivessem de guardar um "segredo". O termo hanseníase encobre o imaginário sobre a lepra, ao mesmo tempo, esse imaginário se mantém latente, como uma ameaça. Isso demonstra a força da palavra sobre as coisas. 


\section{Considerações finais}

Com base nos resultados desta pesquisa, considera-se que os estudos de recepção revelam-se como uma valiosa estratégia comunicativa para os programas de saúde. No contexto da hanseníase, a recepção de materiais educativos por pacientes possibilitou o conhecimento e a compreensão do modo como se dá o processo de produção e apropriação de sentidos sobre o agravo e das práticas preventivas adotadas.

No que se refere aos formatos dos materiais, a cartilha foi identificada como a mais adequada para os pacientes por possibilitar a abordagem de assuntos considerados como verdadeiros "nós" na comunicação sobre a doença, como, por exemplo: os sintomas neurológicos, as complicações provocadas pela doença e associação do termo lepra a hanseníase. Tais resultados explicitam a necessidade de os programas de controle considerarem, no planejamento das atividades preventivas - entre elas as de comunicação -, os fatores clínicos, epidemiológicos, socioculturais, incluindo as diferenças de gênero/sexo, cor/raça.

A leitura coletiva dos materiais contextualizada com as experiências dos participantes possibilitou o debate sobre os efeitos da doença em suas vidas. Constatou-se que a hanseníase provoca alterações físicas e psicológicas que repercutem nas representações socioculturais e afetam os homens e as mulheres de forma diferenciada (White, 2005; Oliveira et al., 2003; Oliveira et al., 1998; Bakirtzief, 1995; Claro, 1995). Estes aspectos também foram identificados em diferentes estudos realizados no Brasil.

Os resultados desta pesquisa, também evidenciaram que o uso das mediações "cultura", "familiaridade", "cotidianidade" e "lógica testemunhal" despertaram maior interesse dos pacientes com os materiais, mas, sobretudo, possibilitaram uma maior interação entre os profissionais de saúde e os portadores de hanseníase, e entre os próprios pacientes. A "situação de interlocução" construída na dinâmica da recepção tornou possível a circulação de afetos, experiências e o fortalecimento do vínculo entre os sujeitos nos processos comunicativos. Nesse processo, a "escuta ativa" (Bakhtin, 2006) e a palavra foram elementos fundamentais na criação de espaços dialógicos, nos quais a subjetividade e as dimensões socioculturais, intrinsecamente relacionadas, atuaram como forças motrizes na ressignificação e negociação de sentidos sobre a hanseníase.

A inclusão da análise de materiais educativos, nas atividades de grupo realizadas nos serviços de saúde, contribui para: otimizar o uso destes recursos nas atividades educativas, ampliar o conhecimento sobre os diferentes agravos, e instituir práticas de cuidado integral à saúde. Concluise que os estudos de recepção de materiais educativos se revelam como uma valiosa estratégia para a descentralização das atividades comunicativas promovidas por programas de saúde, além de possibilitarem a participação de diferentes grupos sociais nas etapas do processo comunicativo.

\section{Colaboradores}

Adriana Kelly Santos realizou as atividades de campo, análise dos dados, estruturação e redação do artigo. Ana Paula Goulart Ribeiro e Simone Monteiro participaram das etapas de estruturação, redação e revisão final do manuscrito.

\section{Referências}

BAKHTIN, M. Marxismo e filosofia da linguagem. São Paulo: Hucitec, 2006.

BAKIRTZIEF, Z. Identificando barreiras para aderência ao tratamento de hanseníase. Cad. Saude Publica, v.12, n.4, p.497-505, 1995. 
BRASIL. Ministério da Saúde. Sistema de Informação de Agravos de Notificação (SINANWEB). Brasília, 2009. Disponível em: <http://dtr2004.saude.gov.br/sinanweb/ tabnet/dh?sinannet/hanseniase/bases/Hansbrnet.def>. Acesso em: 2 jun. 2009.

CANGUILHEM, G. Escritos sobre a medicina. Rio de Janeiro: Forense Universitária, 2005.

CLARO, L.B.L. Hanseníase: representações sociais sobre a doença. Rio de Janeiro: Fiocruz, 1995.

FOUCAULT, M. A ética do cuidado de si como prática de liberdade: ética, sexualidade, política. Rio de Janeiro: Forense Universitária, 2006. (Ditos e Escritos 5).

KELLY-SANTOS, A. A palavra \& as coisas: produção e recepção de materiais educativos sobre hanseníase. 2009. 178 f. Tese (Doutorado) - Escola Nacional de Saúde Pública Sergio Arouca, Fundação Oswaldo Cruz, Rio de Janeiro. 2009.

KELLY-SANTOS, A.; MONTEIRO, S.S.; RIBEIRO, A.P.G. Acervo de materiais educativos sobre hanseníase: um dispositivo da memória e das práticas comunicativas. Interface Comunic., Saude, Educ., v.14, n.32, p.37-51, 2009 a.

KELLY-SANTOS, A.; ROSEMBERG, B.; MONTEIRO, S.S. Significados e usos de materiais educativos sobre hanseníase: a concepção dos profissionais de saúde pública do município do Rio de Janeiro. Cad. Saude Publica, v.25, n.4, p.857-67, 2009 b.

LEAL, O.F. Etnografia da audiência: uma discussão metodológica. In: SOUSA, M.W. (Org.). Sujeito, o lado oculto do receptor. São Paulo: Brasiliense, 1995. p.113-21.

MARTIN-BARBERO, J. Dos meios às mediações: comunicação, cultura e hegemonia. Rio de Janeiro: Editora UFRJ, 2003.

MINAYO, M.C.S. O desafio do conhecimento: pesquisa qualitativa em saúde. São Paulo: Hucitec, 2000.

MOREIRA, M.B.R. Hanseníase versus lepra: o que mudou? 2005. Dissertação (Mestrado) - Faculdade de Saúde, Universidade de Brasília, Brasília. 2005.

OLIVEIRA, M.H.P.; ROMANELLI, G. Os efeitos da hanseníase em homens e mulheres: um estudo de gênero. Cad. Saude Publica, v.14, n.1, p.51-60, 1988.

OLIVEIRA, M.L. et al. (Orgs.). Social representation of Hansen's disease thirty years after the term 'leprosy' was replaced in Brazil. Hist., Ciencias, Saude - Manguinhos, v.10, supl.1, p.41-8, 2003.

PINTO, M.J. Comunicação e discurso: uma introdução à análise de discursos. São Paulo: Hacker Editores, 1999.

SONTAG, S. A doença como metáfora. Rio de Janeiro: Edições Graal, 1984.

VÉRON, E. Fragmentos de un tejido. Barcelona: Gedisa, 2004.

WHITE, C. Explaining a complex disease process: talking to patients about hansen's disease (leprosy) in Brazil. Med. Anthropol. Q., v.19, n.3, p.310-30, 2005. 
SANTOS, A.K.; RIBEIRO, A.P.G.; MONTEIRO, S. Lepra y prácticas de comunicación: estudio de la recepción de materiales educativos en un servicio de salud en Rio de Janeiro . Interface - Comunic., Saude, Educ., v.16, n.40, p.205-18, jan./mar. 2012.

Este estudio analiza la recepción de materiales educativos por portadores de lepra atendidos en la atención primaria de salud en el municipio de Rio de Janeiro. Objetiva identificar la visión de los pacientes sobre los materiales, los significados y las representaciones de este grupo sobre la enfermedad. Se trat de una investigación cualitativa, en 2008, adoptando el referencial de la producción social de los sentidos. Fue realizado un grupo focal para el análisis de 20 materiales destinados a la población y a los pacientes. Los pacientes discutieron sobre los síntomas neurológicos, las complicaciones de la enfermedad y sus efectos en la vida de las personas. Se concluye que el uso de los materiales educativos en las actividades de grupo en el servicio de salud favorece una mejor comprensión de aspectos clínicos, psicológicos y socioculturales sobre la lepra y contribuye para potencializar el dialogo entre usuarios y el equipo de salud.

Palabras clave: Estudio de recepción. Materiales educativos y de divulgación. Comunicación. Lepra.

Recebido em 31/01/2011. Aprovado em 15/04/2011. 